\title{
WOOD THERMODEGRADATION: EXPERIMENTAL ANALYSIS AND MODELING OF MASS LOSS KINETICS
}

\author{
A. Pétrissans ${ }^{1, \diamond}$, R. Younsi ${ }^{2}$, M. Chaouch ${ }^{3}$, P. Gérardin ${ }^{1}$, M. Pétrissans ${ }^{1}$
}

In memoriam of Dr. Manfred SCHWANNINGER

\begin{abstract}
In this study, heat treatment was carried out in a relatively low temperature $\left(230^{\circ} \mathrm{C}\right)$. Mass loss kinetics was studied using equipment, specially conceived to measure sample's mass during the thermal treatment. Laboratory experiments were performed for heating rates of $1^{\circ} \mathrm{C} \mathrm{min}^{-1}$. Mathematical model for kinetics of pyrolysis process was used and validated. During the pyrolysis of dry wood samples under inert atmosphere, measurements of temperature distribution and dynamic weight loss were performed. Five different wood species Fagus sylvatica (Beech), Populus nigra (Poplar), Fraxinus excelsior (Ash), Pinus sylvestris (Pine) and Abies pectinata (Silver Fir) were investigated. The unsteady-state mathematical model equations were solved numerically using the commercial package Femlab 2.0. A detailed discussion of the computational model and the solution algorithm is given. The validity of different model assumptions was analyzed. Experimental results were compared with those calculated by the model. Acceptable agreement was achieved.
\end{abstract}

Keywords: Heat treatment, modeling, reaction kinetics, thermodegradation, wood.

\section{INTRODUCTION}

Wood is commonly used as building and engineering material. Unprotected wood exposed to outdoor conditions undergoes a variety of degradation reactions induced by diverse factors such as light, moisture, heat, oxygen, pollutants (Evans et al. 1992). Moisture contain promotes the fungal attack and leads to sever destruction of wood. In the past, wood preservation has been carried out by chemical treatments, some of them including components that are poisonous for environment and human health. Nowadays, heat treatment of the wood by mild pyrolysis is used as an alternative to chemically impregnated wood materials. It is an effective method to improve biological durability of wood (Finnish Thermowood Association 2003, Momohara et al. 2003, Shi et al. 2007). Wood heat treatment induces chemical modification of main wood constituents. Lignin polymer structure is modified (Zammen et al. 2000, Tjeerdsma and Militz 2005, Nguila et al. 2006, Nguila et al. 2007a, Esteves et al. 2008), the ratio between amorphous and crystalline cellulose is also changed (Fengel and Wegener 1989, Sivonen et al. 2002, Yildiz et al. 2006), hemicelluloses are strongly decomposed (Sivonen et al. 2002, Nuopponen et al. 2004, Gérardin et al. 2007), some products precursors of charcoal appear (Nguila et al. 2007b). These chemical 
modifications confer new properties: improved dimensional stability (Mouras et al. 2002, Esteves et al. 2007, Esteves et al. 2007b), better fungal resistance (Hakkou et al. 2006, Kamdem and Pizzi 2002, Mazela et al. 2003, Welzbacher et al. 2007), some color changes (Mitsui et al. 2001, Bekhta and Niemz 2003, Mitsui et al. 2003, Ayadi et al. 2003, Mitsui et al. 2004), mechanical properties modification (Santos 2000, Yildiz 2002, Unsal and Ayrilmis 2005), wood acquires a hydrophobic character (Mitsui et al. 2001, Bekhta and Niemz 2003, Mitsui et al. 2004, Hakkou et al. 2003, Pétrissans et al. 2003, Hakkou et al. 2005, Kocaefe et al. 2008). Even if wood heat treatment seems simple, there are numerous parameters that control this process. Different methods for wood thermal treatment have been developed in France, Finland, Netherlands and Germany since the middle of the last century (Finnish Thermowood Association 2003). In these processes, wood heat treatment by mild pyrolysis (temperature range between $160^{\circ} \mathrm{C}$ and $260^{\circ} \mathrm{C}$ ) is performed under different process conditions (diversity in the process stages, choice of inert atmosphere (nitrogen or hot gases produced from the heat treatment), wet or dry process, use of oil etc. (Rapp 2001). Chemical reactions involved during mild pyrolysis as well as final properties of the material depend strongly on the treatment temperature and process duration. All through the heat treatment, wood is thermally decomposed at a slow rate (Degroot et al. 1988, Repellin and Guyonnet 2005). The resulting anhydrous mass loss (ML) is representative for physical and chemical wood transformations. Mass loss matches to the advancement of the heat treatment process.

Wood thermal degradation is a complex topic given that the material contains several fractions with different thermal behavior. Authors often distinguish a number of stages (Degroot et al. 1988, Repellin and Guyonnet 2005, Nguila et al. 2009). A phase of elimination of some volatile compounds takes place at temperatures lower than $200^{\circ} \mathrm{C}$. For temperature range of $200-280^{\circ} \mathrm{C}$, hemicelluloses are converted essentially into gases and acetic acid. This step corresponds to the wood roasting. At the temperature range of $250-300^{\circ} \mathrm{C}$, lignin and cellulose are decomposed to give three products: gas, tar and char. Wood thermodegradation leads to an anhydrous mass loss, representative for wood chemical transformation. Properties of heat treated wood depend on the mass loss (Weiland et al. 1998). For this reason, controlling the quality of the heat treated wood means to control precisely the mass loss during the treatment. Thus, the knowledge of the kinetic schemes of wood thermodegradation is required.

The aim of this work is to build up a kinetic model which could be applied to the industrial wood heat treatment processes, and make recommendations concerning the operating temperature and treatment duration in order to obtain a required mass loss. Because of the quantity and the complexity of degradation and polymerization reactions occurring in the wood during the heat treatment (Candelier et al. 2011), the concept is a simplified approximation of real phenomena. Wood thermodegradation is described using a two-stage, semi-global kinetic model. Numerous experiences of heat treatment at $230^{\circ} \mathrm{C}$ under nitrogen were carried out for five wood species (Beech, Poplar, Ash, Pine and Fir). The instantaneous mass loss and temperature were recorded. Experimental data were used to determine model parameters. Finally, a comparison between experimental data and numerical results was proposed.

\section{MATERIAL AND METHODS}

\section{Wood sample}

Heat treatment is carried out on wood panels of large sections, dried in a steam room at $105^{\circ} \mathrm{C}$ until mass stabilization. Panel's dimensions are $250 \times 110 \times 25 \mathrm{~mm}^{3}$ respectively in the longitudinal, tangential and radial directions. Two softwood species Pinus sylvestris (Pine) and Abies pectinata (Silver fir) and three hardwood species Fagus sylvatica (Beech), Populus nigra (Poplar), Fraxinus excelsior (Ash) were used in this study. 


\section{Heat treatment process}

Wood species were thermally treated under nitrogen, by conduction between two metallic heating plates. The device was placed on a precision balance allowing recording of dynamic mass loss and instantaneous temperature. Experimental apparatus was more precisely detailed in a previous work (Chaouch et al. 2010). Instantaneous weight and temperatures (at the surface and in the heart of the sample) are recorded. The heat treatment consists of three successive thermal stability areas. The first one is kept at $105^{\circ} \mathrm{C}$ in order to verify the mass stability (the anhydrous mass). The second one $\left(165^{\circ} \mathrm{C}\right)$ is useful for the thermal homogenization of the panel. The wood roasting was performed at $230^{\circ} \mathrm{C}$.

\section{Mathematical formulation}

Wood thermodegradation is a complex set of degradation and polymerization reactions giving several reaction products (Nguila et al. 2009, Weiland et al. 1998). Knowledge of kinetic schemes describing the thermodegradation process is required for elaboration of predicting tools allowing controlling wood heat treatment. Mathematical modeling of occurring coupled heat and mass transfers are a simplified approximation of real phenomena. Variety of methods based on the thermal analysis of polymer thermodegradation has been developed. An overview of required measurement, kinetic analysis of solid state reaction leading the determination of the reaction order and parameterization of the reaction rate, method's advantages and drawbacks has been proposed in the literature (Liu and Fan 1999, Brown et al. 2000, Vyazovkin et al. 2011). There could be cited the isothermal and the constant heating rate methods (Freeman and Carroll 1958, Coats and Redfern 1964), the multiple heating rate model (Kissinger 1957). Modeling of polymer thermodegradation is often based on global kinetics, since trying to represent full complexity of the process makes no sense. Global kinetics uses the key steps in the overall mass loss process. There is an ongoing debate concerning the determination of the kinetic parameters of the global reactions of wood pyrolysis (Prins et al. 2006, Di Blasi and Lanzetta 1997, Rousset et al. 2006, Grioui et al. 2006). Models available in the literature usually assume that kinetics of all the thermodegradation reactions obey an Arrhenius low defined by its kinetic constant and activation energy (Koufopanos et al. 1991, Prins et al. 2006, Di Blasi and Lanzetta 1997, Rousset et al. 2006, Grioui et al. 2006).

The following section is devoted to the mathematical formulation of coupled heat and mass transfers in wood porous media introducing heat effects due to the reactions of polymer decomposition, production of volatiles and non-degradable solid products. Simplifying assumptions are used for the mathematical formulation:

- Wood sample has a rectangular form characterized by its length $L$, width $l$ and thickness $e$, respectively in the longitudinal, tangential and radial directions. The sample thickness is very weak compared to the other dimension and modeling can be represented in 1D.

- Convection transfer occurring because of the formation of volatiles inside the wood material during the heat treatment is neglected, following the recommendations of Vyazovkin et al. 2011.

- Dimensions of the sample are considered invariable; formation of fissures and cracks is neglected.

- Wood physical and thermal properties respectively the specific heat $C p$ and the wood thermal conductivity $\lambda$ are considered as a linear function of temperature (Koufopanos et al. 1991).

$$
\begin{aligned}
& C p(T)=1112+4.85(T-273) \\
& \lambda(T)=0.13+0.0003(T-273)
\end{aligned}
$$

The macroscopic conservation equation governing heat transfer phenomenon is given by:

$$
\rho(t) C p(T) \frac{\partial T}{\partial t}=\frac{\partial}{\partial x}\left(\lambda(T) \frac{\partial T}{\partial x}\right)+H p \frac{\partial \rho(t)}{\partial t}
$$


Where: $\rho(t)=m(t) / V$ is the averaged anhydrous wood density, $T$ is the local temperature; $H p$ is the global reaction enthalpy. The instantaneous sample weight $m(t)$ is detailed by the Eq. (11). Sample's volume $V$ is considered invariable.

Mechanism adopted in this work is based on a two-stage, semi-global multi-reaction kinetic model of wood mild pyrolysis. Actually; it is not possible to identify the exact mechanism of simultaneous degradation of wood main polymers (hemicelluloses, lignin, and cellulose). Then, wood is assumed to be subdivided into three pseudo-components $A_{1}, A_{2}, A_{3}$, as it was previously done by (Grioui et al. 2006). Each pseudo-component is characterized by a specific kinetic law of decomposition and a mass fraction: $\alpha_{1}=m_{A 1} / m_{0}, \alpha_{2}=m_{A 2} / m_{0}$ and $\alpha_{3}=m_{A 3} / m_{0}$ such as $\alpha_{1}+\alpha_{2}+\alpha_{3}=1 . m_{A l}, m_{A 1}, m_{A 3}$ and are the masses of pseudo constituents $A_{1}, A_{2}, A_{3}$ in the native wood (before treatment) and $m_{0}$ is the mass of the native anhydrous wood sample. At a temperature lower than $200^{\circ} \mathrm{C}$ occurs the elimination of some volatile wood compounds. At the temperature range of 165 to $230{ }^{\circ} \mathrm{C}$, the degradation of $A_{1}$ prevails giving a gaseous product $G_{1}$. The thermo-degradation of $A_{2}$ leads to the production of a solid fraction $C_{2}$ and a gas product $G_{2}$. Proposed kinetic scheme is given by Eq. (4-5):

$$
\begin{gathered}
A_{1} \stackrel{k_{1}}{\longrightarrow} G_{1} \\
A_{2} \stackrel{k_{2}}{\longrightarrow} \gamma_{2} C_{2}+\left(1-\gamma_{2}\right) G_{2}
\end{gathered}
$$

Mass fraction of non-degradable solid $\gamma_{2}$ depends on the operating temperature. With the assumption that kinetic of all involved reactions is described by a first order law, mass balance equations can be written:

$$
\begin{aligned}
& \frac{\mathrm{d} m_{A_{1}}(t)}{\mathrm{dt}}=-k_{1} m_{A_{1}}(t) \\
& \frac{\mathrm{d} m_{A_{2}}(t)}{\mathrm{dt}}=-k_{2} m_{A_{2}}(t) \\
& \frac{\mathrm{d} m_{C_{2}}(t)}{\mathrm{dt}}=k_{2} \gamma_{2} m_{A_{2}}(t)
\end{aligned}
$$

Where, $m_{A I}(t), m_{A 2}(t)$ and $m_{C 2}(t)$, are the instantaneous mass of the constituents $A_{1}, A_{2}$ and $C_{2} ; k_{1}$ and $k_{2}$ are the reaction rate constants obeying an Arrhenius low such as:

$$
\begin{aligned}
& k_{1}=k_{01} \exp \left(-\frac{E a_{1}}{R T}\right) \\
& k_{2}=k_{02} \exp \left(-\frac{E a_{2}}{R T}\right)
\end{aligned}
$$

Where, $k_{01}$ and $k_{02}$ are the pre-exponential factors; $E a_{1}$ and $E a_{2}$ are the activation energies of global thermo degradation reactions of pseudo constituents $A_{1}$ and $A_{2}$. Instantaneous total sample mass is equal to: 


$$
m(t)=m_{A_{A}}(t)+m_{A_{2}}(t)+m_{A_{3}}(t)+m_{C_{2}}(t)
$$

The resolution of the Eq. (3-10) requires the determination of 8 parameters: pre-exponential factors $k_{01}, k_{02}$, and activation energies $E a_{1}, E a_{2}$, mass fraction fractions $\alpha_{1}, \alpha_{2}$ and $\gamma_{2}$; reaction enthalpy $H p$ of the global process. In this work, kinetics parameters haven't been derived by classic thermal analysis (Brown et al. 2000, Vyazovkin et al. 2011) but numerically, by minimizing the error function between the experimental data and simulation results Eq. (12):

$$
\text { error }_{\text {global }}=\frac{1}{n_{1}} \sum_{i=1}^{n_{1}} \frac{2\left|T_{\exp }(i)-T_{\text {calculated }}(i)\right|}{\left(T_{\exp }(i)+T_{\text {calculated }}(i)\right)}+\frac{1}{n_{2}} \sum_{j=1}^{n_{2}} \frac{2\left|M L_{\text {exp }}(j)-M L_{\text {calculated }}(j)\right|}{\left(M L_{\exp }(j)+M L_{\text {calculated }}(j)\right)}
$$

where $n_{1}$ is the number of data points of the temperature, $T_{\text {exp }}(i)$ is the experimental temperature, $\mathrm{T}_{\text {calculated(i) }}$ is the calculated temperature on the $i$-th grid point, $n_{2}$ is the number of data points of the mass loss $M L_{\text {exp }}(j)$ and $M L_{\text {calculated }}(j)$ are respectively experimental and the calculated mass loss due to the thermo-degradation on the $j$-th grid point. The anhydrous mass lost is defined as follows:

$$
M L=\left(m_{0}-m(t)\right) / m_{0}
$$

Experiences are carried out in a way, allowing the determination of model parameters over two stages. At the second isothermal area at $165^{\circ} \mathrm{C}$, the reaction giving by the Eq. (5) can be neglected because of its very slow rate. It has been also considered that reaction enthalpy of this reaction is negligible. Three parameters relative to the first reaction (Eq. 4) are then determined: $\alpha_{l}, k_{01}$ and $E a_{1}$. The third isothermal area at $230^{\circ} \mathrm{C}$, corresponding to the heat treatment process, allows the determination of the five other parameters: $\alpha_{2}, \gamma_{2}, k_{02}, E a_{2}$ and $H p$. Governing equations are solved numerically with the commercial package Femlab 2.0. This is designed to simulate systems of coupled non-linear and time dependent partial differential equations (PDE) in one-, two- or three- dimensions. The mesh convergence was verified with refined mesh sizes.

Time step of 360 s, 1866 nodes and 8080 elements mesh size were considered to be appropriate.

\begin{tabular}{|c|c|c|c|c|c|c|c|c|}
\hline Species & $\alpha_{1}$ & $\alpha_{2}$ & $\begin{array}{c}\mathbf{E}_{\mathrm{a} 1} \\
\left(\mathrm{kJ.mol}^{-1}\right)\end{array}$ & $\begin{array}{c}\mathbf{E}_{\mathrm{a} 2} \\
\left(\mathbf{k J} . \mathrm{mol}^{-1}\right)\end{array}$ & $\begin{array}{l}\mathbf{k}_{01} \\
\left(\mathrm{~s}^{-1}\right)\end{array}$ & $\begin{array}{l}\mathbf{k}_{02} \\
\left(\mathrm{~s}^{-1}\right)\end{array}$ & $\gamma$ & 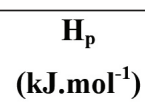 \\
\hline Ash & 0,090 & 0,150 & 119,0 & 120,0 & $1,810^{8}$ & $1,010^{9}$ & 0,070 & 113,0 \\
\hline Beech & 0,080 & 0,145 & 119,0 & 120,0 & $0,610^{8}$ & $7,510^{8}$ & 0,070 & 113,0 \\
\hline Pine & 0,070 & 0,100 & 119,0 & 120,0 & $0,510^{8}$ & $8,010^{8}$ & 0,070 & 120,0 \\
\hline Fir & 0,080 & 0,100 & 119,0 & 119,0 & $0,610^{8}$ & $1,010^{9}$ & 0,070 & 113,0 \\
\hline Poplar & 0,080 & 0,120 & 118,5 & 119,0 & $4,010^{7}$ & $6,010^{8}$ & 0,070 & 123,0 \\
\hline
\end{tabular}
The kinetic parameters obtained with this method are given in table 1:

Table 1. The kinetic parameters used in the numerical simulation for the five species. 


\section{RESULTS AND DISCUSSION}

In order to verify the final weight loss predicted by the model, experiments with a reaction time of 20 hours were carried out (including a drying period at $105^{\circ} \mathrm{C}$, a stabilization phase at $165^{\circ} \mathrm{C}$ and the heat treatment at $230^{\circ} \mathrm{C}$ ). The comparison between experimental data and simulation results was performed for five species. Results are shown in figure (1-5). Careful consideration of the experimental weight curves reveals that they do not become completely horizontal; the weight continues to decrease very slowly. Hardwoods (Figure 3-5) were shown to be more sensitive to thermodegradation than softwoods (Figure 1-2). Softwoods degradation products appear at slightly higher temperature. These physical phenomena were reproduced by the simulation; a good agreement was obtained.
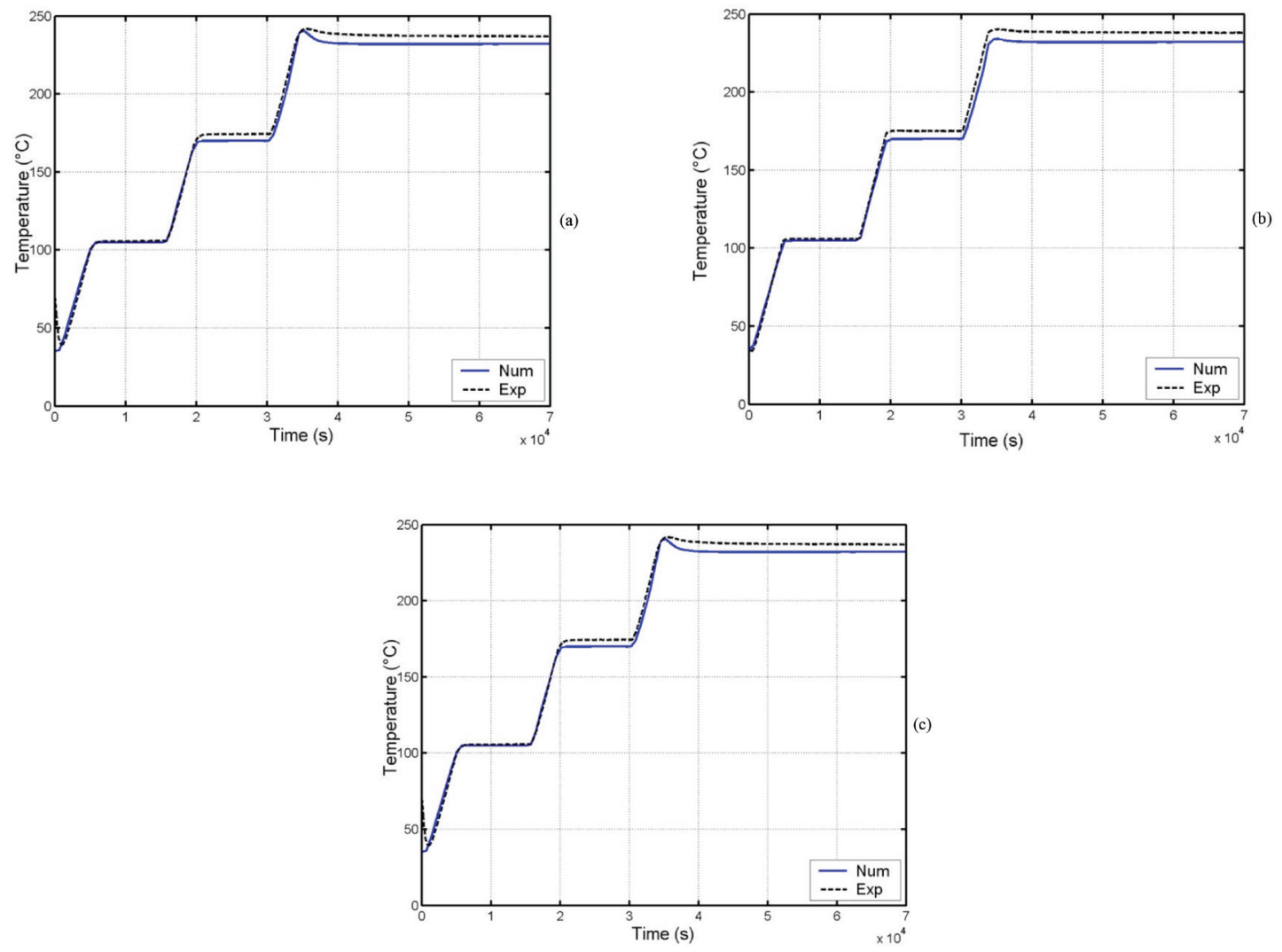

Figure 1. Fir -average mass loss (a), surface temperature (b), center temperature (c). 

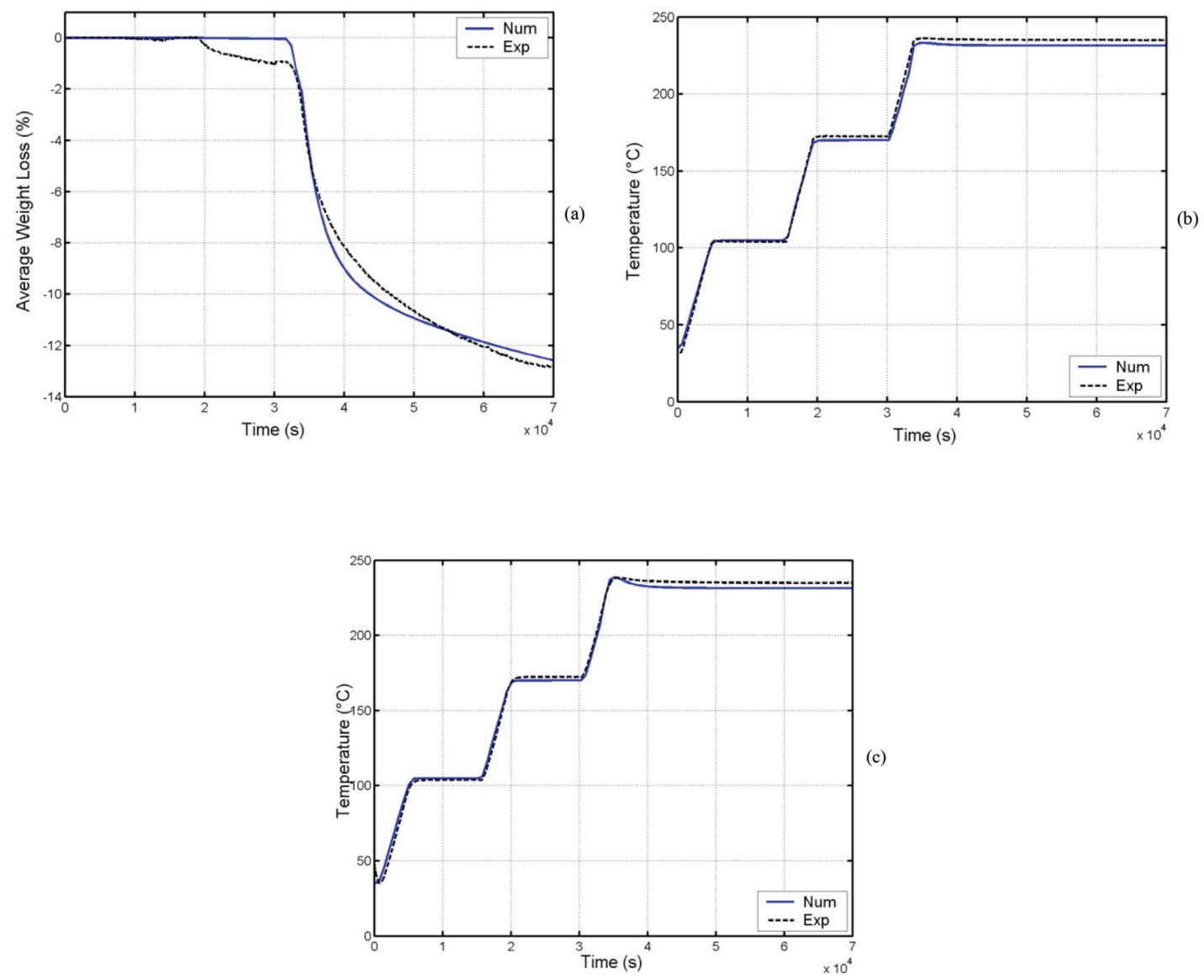

Figure 2. Pine - average mass loss (a), surface temperature (b), center temperature (c). 

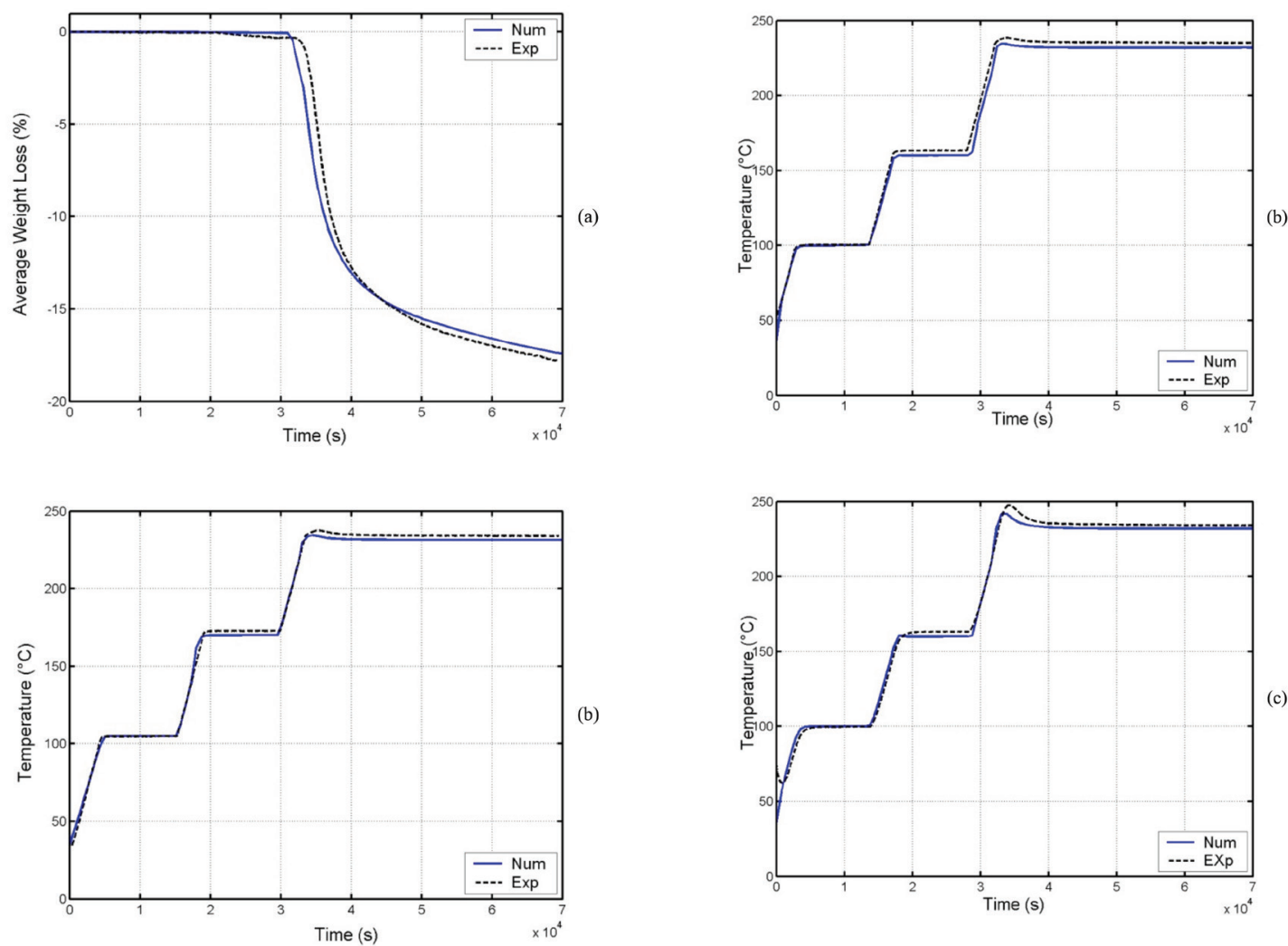

Figure 3. Poplar - average mass loss (a), surface temperature (b), center temperature (c). 

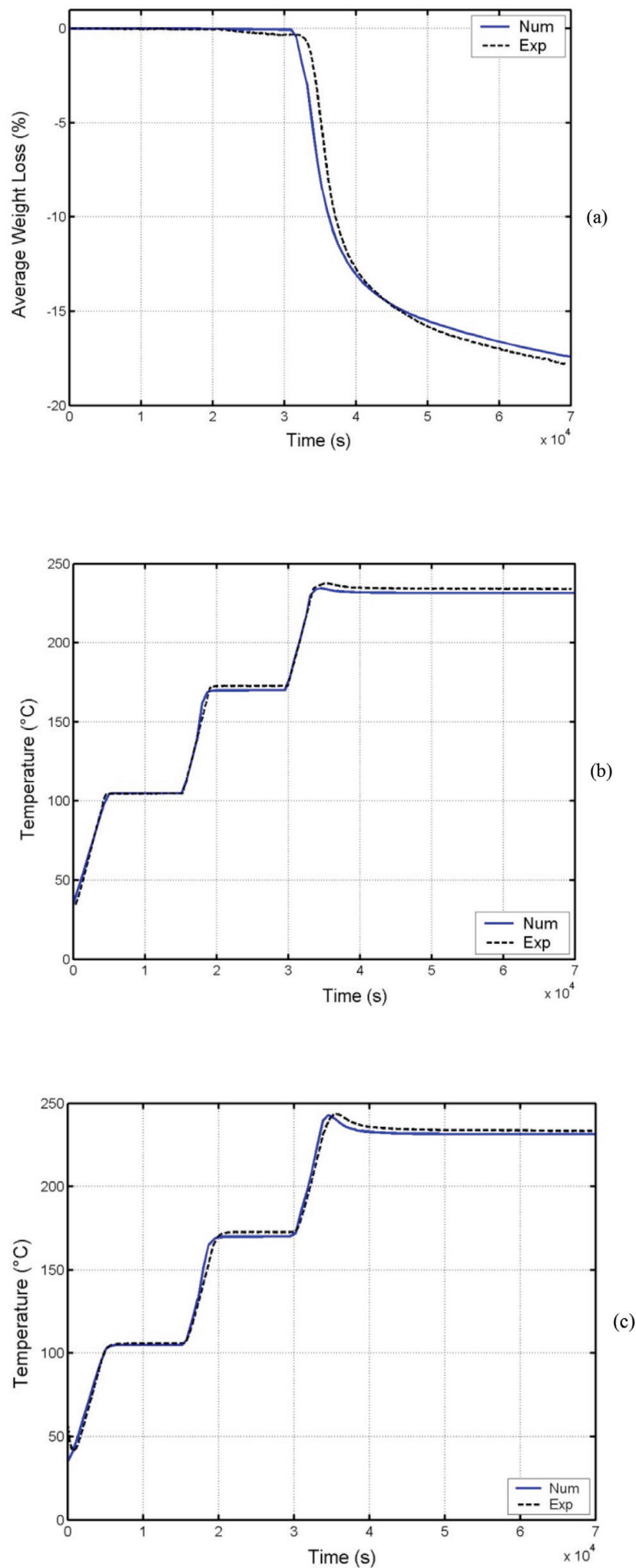

Figure 4. Beech - average mass loss (a), surface temperature (b), center temperature (c). 


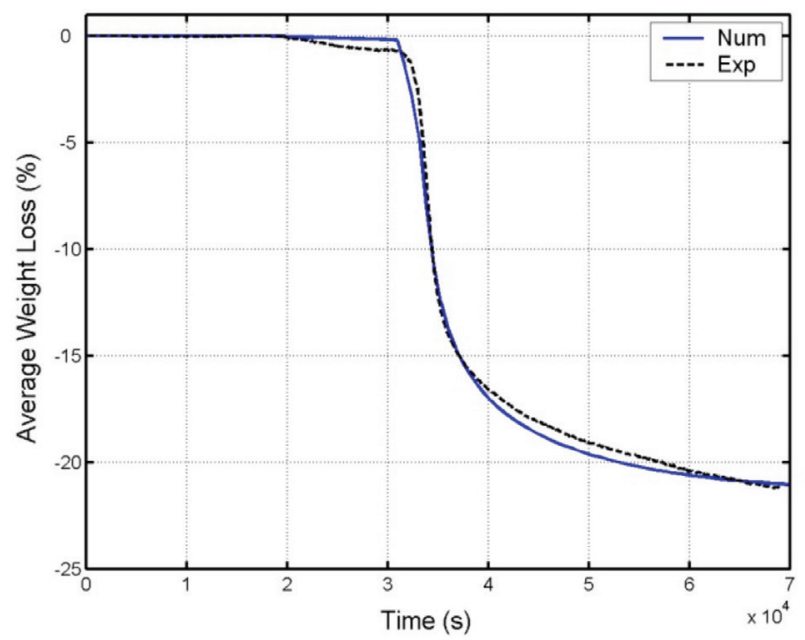

(a)

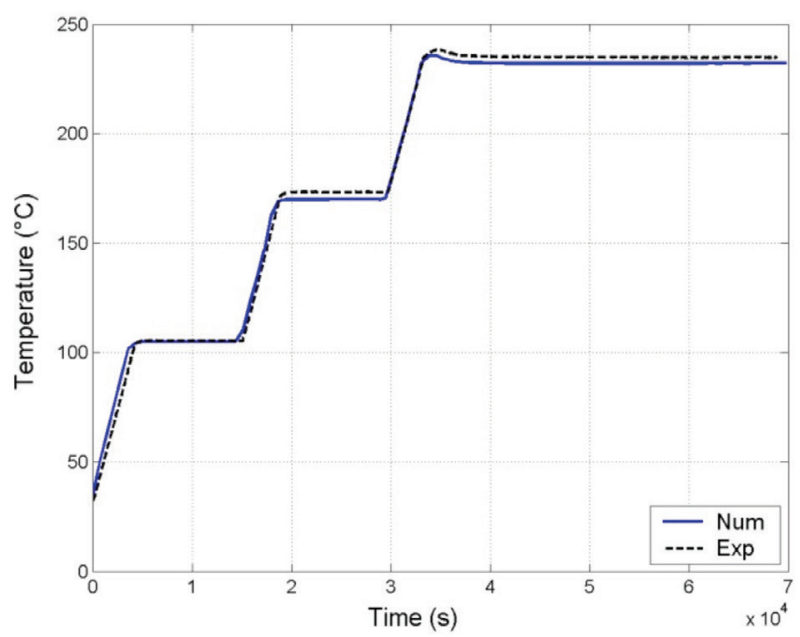

(b)

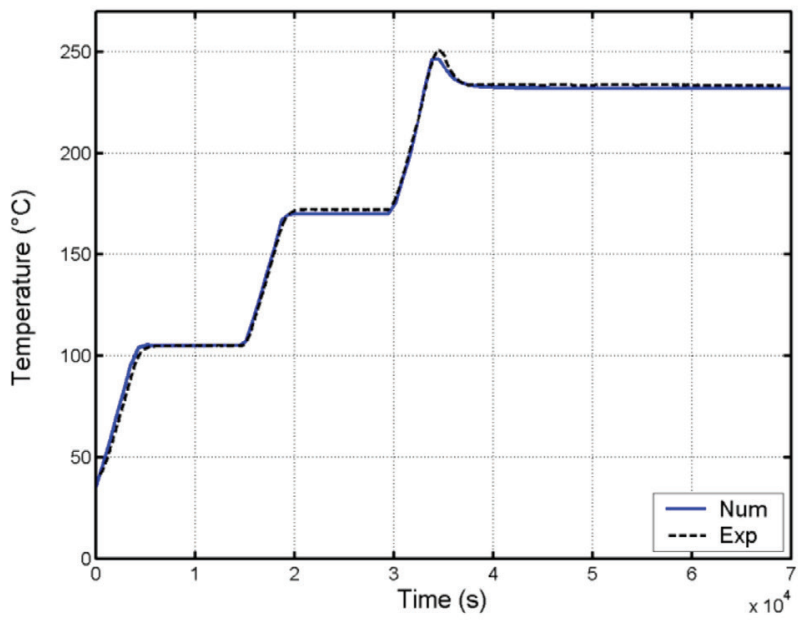

(c)

Figure 5. Ash - average mass loss (a), surface temperature (b), center temperature (c). 
Concerning the observation of temperature evolution recorded data, it is important to pay attention on the existence of an exothermic peak. This temperature rising is more pronounced in the sample heart, it could be probably due to the heat produced by the reaction of wood thermodegradation which activates the exothermic degradation reactions, obeying themselves to the Arrhenius low. The temperature control of the heating plates attenuates this effect on the sample surface. The coupled consideration of integrated in the model heat and mass transfers allows a good representation of this exothermic phenomenon.

\section{CONCLUSION}

The kinetics of wood pyrolysis in a temperature of $230^{\circ} \mathrm{C}$ can be described accurately by the proposed two-step reaction mechanism. The model incorporates the reaction pathway that was developed by Grioui et al. (2006) describing wood transformation during the mild pyrolysis. The model allows the computation of temperature profiles and average weight loss. Femlab 2.0 software was used to solve the system of partial differential equations. This paper includes a validation section that shows the ability of the model to accurately predict temperature profiles and mass loss in the experimental configuration. Comparison between simulated results and experimentally measured values showed a good agreement.

This model requires a preliminary determination of the reaction kinetics parameter for each softwood or hardwood species. However, the model can be used as an accurate tool in the design of industrial pyrolysis installations.

\section{ACKNOWLEDGMENTS}

LERMaB is supported by the French National Research Agency through the Laboratory of Excellence ARBRE (ANR-12- LABXARBRE-01), the authors gratefully acknowledge this aid. 


\section{REFERENCES}

Ayadi, N.; Lejeune, F.; Charrier, F.; Charrier, B.; Merlin, A. 2003. Colour stability of heat treated wood during artificial weathering. Holz als Roh- und Werkstoff 61 (3): 221-226.

Bekhta, P.; Niemz, P. 2003. Effect of high temperature on the change in color, dimensional Stability and mechanical properties of spruce wood. Holzforshung 57 (5): 539-546.

Brown, M.E.; Maciejewski, M.; Vyazovkin, S.; Nomen, R.; Sempere, J.; Burnham, A.; Opfermann J.; Strey R.; Anderson, H.L.; Kemmler, A.; Keuleers, R.; Janssens, J.; Desseyn, H.O.; Chao-Rui, Li; Tong, T.; Roduit, B.; Malek, J.; Mitsuhashi, T. 2000. Computational aspects of kinetic analysis Part A: The ICTAC kinetics project-data, methods and results. Thermochimica Acta 355: 125-143.

Candelier, K.; Chaouch, M.; Dumarçay, S.; Pétrissans, A.; Pétrissans, M.; Gérardin, P. 2011. Utilization of thermodesorption coupled to GC-MS to study stability of different wood species to thermodegradation. Journal of Analytical and Applied Pyrolysis 92(2): 376-383.

Chaouch, M.; Pétrissans, M.; Pétrissans, A.; Gérardin, A. 2010. Use of wood elemental composition to predict heat treatment intensity and decay resistance of different softwood and hardwood species. Polymer Degradation and Stability 95: 2255-2259.

Coats, A.V.; Redfern, J.P. 1964. Kinetic parameters from thermogravimetric data. Nature 201: 68-69.

Degroot, W.F.; Pan, W.P.; Rahman, D.; Richards, G.N. 1988. First chemical events in pyrolysis of wood. Journal of Analytical and Applied Pyrolysis 13: 221-231.

Di Blasi, C.; Lanzetta, M. 1997. Intrinsic kinetics of isothermal xylan degradation in inert atmosphere. Journal of Analytical and Applied Pyrolysis 40-41: 287-303.

Esteves, B.; Graça, J.; Pereira, H. 2008. Extractive composition and summative chemical analysis of thermally treated eucalypt wood. Holzforshung 62 (1): 344-351.

Esteves, B.; Domingos, I.; Pereira, H. 2007a. Improvement of technological quality of eucalypt wood by heat treatment in air at $170-200^{\circ}$ C. Forest Products Journal 57 (1-2): 47-52.

Esteves, B.; Velez Marques, A.; Dominigos, I.; Pereira, H. 2007b. Influence of steam heating on the properties of pine (Pinus pinaster) and eucalypt (Eucalyptus globulus) wood. Wood Science and Technology 41 (2): 193-207. 
Evans, P.D.; Michell, A.J.; Schmaltz, K.J. 1992. Studies of degradation and protection of wood surfaces. Wood Science and Technology 26: 151-163.

Fengel, D.; Wegener, G. 1989. Wood-Chemistry, Ultrastructure, Reactions. Ed. Walter de Gruyter, Berlin, Germany.

Finnish Thermowood Association, ThermoWood Handbook. Helsinki-Finland. 2003. [on line]<http://www.thermowood.fi/data.php/200312/795460200312311156_tw_handbook.pdf>.

Freeman, E.S.; Carroll, B. 1958. The Application of Thermoanalytical Techniques to Reaction Kinetics: The Thermogravimetric Evaluation of the Kinetics of the Decomposition of Calcium Oxalate Monohydrate. Journal of Physical Chemistry 62 (4): 394-397.

Gérardin, P.; Petric, M.; Petrissans, M.; Erhrardt, J.J.; Lambert, J. 2007. Evolution of wood surface free energy after heat treatment. Polymer degradation and stability 92 (4): 653-657.

Grioui, N.; Halouani, K.; Zoulalian, A.; Halouani, F. 2006. Thermogravimetric analysis and kinetics modeling of isothermal carbonization of olive wood in inert atmosphere. Thermochimica Acta 440: 23-30.

Hakkou, M.; Pétrissans, M.; Gérardin, P.; Zoulalian, A. 2006. Investigations of the reasons for fungal durability of heat-treated beech wood. Polymer degradation and stability 91: 393-397.

Hakkou, M.; Pétrissans, M.; El Bakali, I.; Gérardin, P.; Zoulalian, A. 2003. Evolution of wood hydrophobic properties, during heat treatment of wood. In: Abstract of the First European conference on wood modification. Ghent, Belgium.

Hakkou, M.; Pétrissans, M.; Gérardin, P.; Zoulalian, A. 2005. Investigation of wood wettability changes during heat treatment on the basis of chemical analysis. Polymer degradation and stability 89 (1): $1-5$.

Kamdem, D.P.; Pizzi, A.; Jermannaud, A. 2002. Durability of heat-treated wood. Holz als Rohund Werkstoff 60: 1-6.

Kissinger, H.E. 1957. Cinétique de réaction dans l'analyse thermique différentielle. Analytical Chemistry 29: 1702-1706.

Kocaefe, D.; Poncsak, S.; Boluk, Y. 2008. Effect of thermal treatment on the chemical composition and mechanical properties of birch and aspen. Bioresource 3 (2): 517-537. 
Koufopanos, C.A.; Papayannakos, N.; Maschio, G.; Lucchesi, A. 1991. Modelling of the pyrolysis of biomass particles: studies on kinetics, thermal and heat transfer effects. Canadian Journal of Chemical Engineering 69 (4): 907-915.

Liu, N.A.; Fan, W.C. 1999. Critical consideration on the Freeman and Carroll method for evaluating global mass loss kinetics of polymer thermal degradation. Thermochimica Acta 338: 85-94.

Mazela, B.; Zakrzewski, R.; Grzeskowiak, W.; Cofta, G., Bartkowiak, M. 2003. Preliminary research on the biological resistance of heatly modified wood. In: Abstracts of the First European Conference on Wood modification, Ghent, Belgium.

Mitsui, K.; Takada, H.; Sugiyama, M.; Hasegawa, R. 2001. Changes in the properties of lightirradiated wood with heat treatment: Part 1. Effect of treatment conditions on the change in color. Holzforshung 55 (6): 601-605.

Mitsui, K.; Murata, A.; Kohara, M.; Tsuchikawa, S. 2003. Colour modification of wood by lightirradiation and heat treatment. In: Abstracts of the First European Conference on Wood Modification, Ghent, Belgium.

Mitsui, K.; Murata, A.; Tolvaj, L. 2004. Changes in the properties of light-irradiation wood with heat treatment: Part 3. Monitoring by DRIFT spectroscopy. Holz als Roh- und Werkstoff 62 (3): 164-168.

Momohara, I.; Ohmura, W.; Kato, H.; Kubojima, Y. 2003. Effect of High-Temperature Treatment on Wood Durability against the Brown-rot Fungus, Fomitopsis palustris, and the Termite, Coptotermes formosanus. In: 8th International IUFRO Wood Drying Conference, 284-287.

Mouras, S.; Girard, P.; Rousset, P.; Permadi, P.; Dirol, D.; Labat, G. 2002. Propriétés physiques de bois peu durables soumis à un traitement de pyrolyse ménagée. Annals of Forest Sciences 59 (3): 317-326.

Nguila, I.G.; Pétrissans, M.; Lambert, J.L.; Erhardt, J.J.; Gérardin, P. 2006. XPS Characterization of wood chemical composition after heat treatment. Surface \& Interface Analysis 38 (10): 1336-1342.

Nguila, I.G.; Pétrissans, M.; Gérardin, P. 2007a. Chemical reactivity of Heat treated Wood. Wood Science Technology 41 (2): 157-168.

Nguila, I.G.; Mounguengui, S.; Dumarcay, S.; Pétrissans, M.; Gérardin, P. 2007b. Evidence of char formation during wood heat treatment by mild pyrolysis. Polymer Degradation and Stability 92 (6): 997-1002. 
Nguila, I.G.; Pétrissans, M.; Pétrissans, A.; Gérardin, P. 2009. Elemental composition of wood as a potential marker to evaluate heat treatment intensity. Polymer Degradation and Stability 94 (3): 365-368

Nuopponen, M.; Vuorinen, T.; Jamsa, S.; Viitaniemi, P. 2004. Thermal modifications in softwood studied by FT-IR and UV resonance raman spectroscopie. Journal of Wood Chemistry and Technology 24(1): 13-26.

Pétrissans, M.; Gérardin, P.; El Bakali, I.; Serraj, M. 2003. Wettability of heat-treated wood. Holzforschung 57 (3): 301-307.

Prins, M.J.; Ptasinski, K.J.; Janssen, F.J.J.G. 2006. Torrefaction of wood. Part 1. Weight loss kinetics. Journal of Analytical and Applied Pyrolysis 77 (1): 28-34.

Rapp, A.O. 2001. Review on heat treatment of wood. Proceeding of seminar held on Antibes, France, 9 February.

Repellin, V.; Guyonnet, R. 2005. Evaluation of heat-treated wood swelling by differential scanning calorimetry in relation to chemical composition. Holzforschung 59 (1): 28-34.

Santos, A.J. 2000. Mechanical behavior of Eucalyptus wood modified by heat. Wood Science and Technology 34 (1): 39-43.

Sivonen, H.; Maunu, S.L.; Sundholm, F.; Jämsä, S.; Viitaniemi, P. 2002. Magnetic resonance studies of thermally modified wood. Holzforschung 56 (6): 648-654.

Shi, J.L.; Kocaefe, D.; Amburgey, T.; Zhang, J. 2007. A comparative study on brownrot fungus decay and subterranean termite resistance of thermally-modified and ACQ-C-treated wood. Holz als Roh- und Werkstoff 65 (5): 353-358.

Tjeerdsma, B.; Militz, H. 2005. Chemical changes in hydroheat wood: FTIR analysis of combined hydroheat and dry heat-treated wood. Holz Roh Werkst 63 (2): 102-111.

Unsal, O.; Ayrilmis, N. 2005. Variations in compression strength and surface roughness of heattreated Turkish river red gum. Journal of Wood Science 51 (4): 405-409.

Vyazovkin, S.; Burnham, A.K.; Criado, J.M.; Pérez-Maqueda, L.A.; Popescu, C.; Sbirrazzuoli, N. 2011. ICTAC Kinetics Committee recommendations for performing kinetic computations on thermal analysis data. Thermochimica Acta 520: 1-19. 
Weiland, J.J.; Guyonnet, R.; Gibert, R. 1998. Analysis of controlled wood burning by combination of thermogravimetric analysis, differential scanning calorimetry and Fourier transform infrared spectroscopy. Journal of Thermal Analysis and Calorimetry 51 (1): 265-274

Welzbacher, C.; Brischke, C.; Rapp, A. 2007. Influence of treatment temperature and duration on selected biological, mechanical, physical and optical properties of thermally modified wood. Wood Material Science and Engineering 2 (2): 66-76.

Yildiz, S. 2002. Effects of heat treatment on water repellence and anti-swelling efficiency of beech wood. IN: International Research Group on Wood Preservation, Section 4-Processes, NIRG/WP 0240223 .

Yildiz, S.; Gezer, D.; Yildiz, U. 2006. Mechanical and chemical behaviour of spruce wood modified by heat. Building and Environment 41 (12): 1762-1766.

Zammen, A.; Alen, R.; Kotilainen, R. 2000. Heat behavior of Pinus sylvestris and Betula pendula at $200-230^{\circ} \mathrm{C}$. Wood and Fiber Science 32 (2): 138-143. 